Western Washington University Western CEDAR

Summer 7-3-2020

\title{
Adventure in the Age of COVID-19: Embracing Microadventures and Locavism in a Post-Pandemic World
}

Jasmine Goodnow

Western Washington University, jasmine.goodnow@wwu.edu

Susan Houge Mackenzie

University of Otago

Follow this and additional works at: https://cedar.wwu.edu/healthandhumandev_facpubs

Part of the Health and Physical Education Commons

\section{Recommended Citation}

Susan Houge Mackenzie \& Jasmine Goodnow (2020): Adventure in the Age of COVID-19: Embracing Microadventures and Locavism in a Post-Pandemic World, Leisure Sciences, DOI: 10.1080/ 01490400.2020 .1773984

This Article is brought to you for free and open access by the Social and Behavioral Sciences at Western CEDAR. It has been accepted for inclusion in Health and Human Development by an authorized administrator of Western CEDAR. For more information, please contact westerncedar@wwu.edu. 


\title{
Adventure in the Age of COVID-19: Embracing Microadventures and Locavism in a Post-Pandemic World
}

\author{
Susan Houge Mackenzie ${ }^{\mathrm{a}}$ and Jasmine Goodnow ${ }^{\mathrm{b}}$ \\ ${ }^{a}$ Department of Tourism, University of Otago, Dunedin, New Zealand; ${ }^{b}$ Department of Health and \\ Human Development, Western Washington University, Bellingham, WA, USA
}

\begin{abstract}
Unprecedented mobility restrictions due to COVID-19 have frozen the adventure travel and tourism industry. These restrictions have forced many to embrace 'hyperlocal' approaches to adventure and provided an opportunity to reimagine our adventure travel philosophies and practices. Despite claims that traditional adventure travel could address some of the "world's most pressing challenges", it has largely failed to realize its potential to provide a range of social, economic, and environmental benefits. Conversely, microadventure, which espouses adventures in nearby nature that are low-carbon and human-scaled, is an enticing alternative for both current and post-pandemic conditions. This essay first critiques pre-pandemic adventure travel and describes the hazards of this approach in age of COVID-19. It then explores creative 'lockdown' microadventures; envisions what post-pandemic adventure may look like; and explains why we not only need to embrace microadventures in a post-pandemic world, but also why we may prefer them to traditional adventure travel.
\end{abstract}

\section{ARTICLE HISTORY}

Received 22 April 2020

Accepted 9 May 2020

\section{KEYWORDS}

Adventure tourism; coronavirus; COVID-19; microadventure; sustainable tourism

It is time to reimagine adventure. The COVID-19 pandemic fundamentally questions the importance of discretionary travel for leisure and personal well-being. Prior to recent unprecedented mobility restrictions, adventure travel (e.g., travel to undertake novel, physically challenging activities in remote natural environments) experienced significant growth. This growth was fueled not only by demand from individual's seeking adventure benefits (e.g., nature connection, self-development, well-being), but also by proposed supply-side benefits. Adventure travel was touted for its "vast potential ... to address some of the world's most pressing challenges, including socioeconomic growth, inclusive development and environmental preservation" (WTO, 2014, p. 10). Nevertheless, the rationale for extended travel requiring significant equipment, finances, and emissions to fragile environments and communities for personal development is questionable across environmental and social justice fronts. The 'microadventure' movement, which has gained traction in Europe and North America since 2016, emerged in 
response to these dilemmas. It espouses "adventure that is close to home, cheap, simple, short, and ... effective. It still captures the essence of big adventures, the challenge, the fun, the escapism, the learning experiences and the excitement" (Humphreys, 2014, p. 14). This movement reconceptualises adventure from being 'out there' (i.e., remote, time and resource intensive) to 'right here' (i.e., local, attainable) and reflects broader calls for locavism: short distance, lower-carbon travel that retains financial and social capital locally (Hollenhorst, Houge Mackenzie \& Ostergren, 2014).

COVID-19 has forced many to embrace locavist approaches to adventure on the most micro level. Some have rediscovered opportunities for nearby nature-based adventures via human-scaled mobility. In contrast, traditional adventure travel practices in the age of COVID-19 have potentially disastrous outcomes for public health systems, particularly in remote communities. These juxtaposed approaches are epitomized by reports of wilderness areas overrun by visitors seeking remote nature-based adventure at any cost during lockdowns. In addition to seeking adventure in remote areas, the increasing numbers of people seeking refuge from COVID-19 in isolated communities has sparked debates regarding the ethics of tourism in these areas. At the crux of these debates are issues of social responsibility in relation community quality-of-life, the livelihoods of people dependent on tourism, and the rights of second home owners in vulnerable areas. This commentary critiques traditional, pre-pandemic adventure travel in the age of COVID-19 and explores the benefits of microadventures for a post-pandemic world.

\section{Past: pre-pandemic adventure}

Pre-pandemic, adventure travel was experiencing significant global growth. The adventure travel industry grew by $195 \%$ from 2010 to 2014 and was forecast to grow a further 33\% by 2023 (Allied Market Research, 2018; WTO, 2014). While 'adventure' has various academic and popular definitions, uncertainty, skill development, novelty, unique physical and mental challenges (often framed as 'risk'), and natural environments are oft cited elements (e.g., Boudreau et al., 2020). Traditionally, it has also involved extended travel to remote environments and communities (e.g., Rantala, Rokenes, \& Valkonen, 2018). Increases in adventure travel were largely driven by the individual benefits attributed to these novel experiences, such as personal transformations; enhanced self-esteem, self-confidence, intrinsic motivation, resilience, and well-being; and, more recently, ecocentric perspectives (e.g., Brymer \& Schweitzer, 2013; Ewert \& Yoshino, 2011; Houge Mackenzie \& Brymer, 2020). Adventure travel was also fueled by desires for escape and liminality, a state of transition characterized by the absence of boundaries, social conventions, and daily constraints (Turner, 1966). As liminality is achieved by either physically entering a novel environment and/or cognitively disconnecting from normal environments and thought processes, the natural environments and immersive activities inherent in adventure are highly conducive to liminality (e.g., Bloom \& Goodnow, 2013; Goodnow \& Bordoloi, 2017; White \& White, 2004).

In addition to promising personal growth, adventure travel was portrayed as an archetype of environmentally sustainable, socially responsible travel amidst the antipathy of mass tourism. This idealized form of travel was promoted on the basis of its triplebottom line benefits by bolstering local economies, preserving pristine environments, 
and empowering communities (e.g., Dwyer, 2005; Stoddard, Pollard, \& Evans, 2012; WTO, 2014). Despite these utopian ideals, adventure travel has been critiqued for contributing to the very environmental, social and economic issues is purports to mitigate. This type of resource-intensive travel, largely undertaken by well-off Western clients, presents a host of environmental and social justice issues, ranging from commodification of cultural artifacts and destruction of fragile ecosystems, to modern day colonialism (e.g., Williams \& Soutar, 2005).

The microadventure movement evolved in response to many issues posed by traditional adventure travel. Microadventures are rewarding short-term adventures completed close to home "in normal places for Normal People" (Humphreys, 2014, pp. 16 17). Allister Humphreys coined this term when, after decades of adventure travel, he began a family and replaced extended, remote adventures with shorter, closer familyfriendly adventures that retained the spirit of 'grand adventure' and core benefits, such as liminality, novelty, perspective shifting, and escape. Microadventure concepts and practices, ranging from solo to multi-generational adventures, have since been increasingly embraced across all ages, abilities, and family stages, particularly by time-poor Europeans (Euromonitor, 2016). This approach is more inclusive as it addresses three primary hurdles to traditional adventure (mobility/access, time, and money) and avoids common criticisms such as carbon emissions, damage to unique ecosystems, social disruptions, cultural commodification/exploitation, and economic leakage (e.g., Roberts, 2018; Williams \& Soutar, 2005). There is also evidence that microadventures facilitate similar psychological benefits to traditional adventure experiences (e.g., Goodnow \& Bordoloi, 2017; Roberts, 2018). Rather than relying on extended durations and exotic environments to achieve traditional adventure benefits, microadventures hinge on activity novelty and participant mindset (e.g., degree to which participants' cognitively or emotionally disconnect from everyday life). Microadventures also exemplify Hollenhorst et al.'s (2014) broader calls for locavism: bioregional tourism undertaken close to home. Locavism was proposed as a climate-friendly antidote to fast, high-carbon travel predicated on superficial experiences in long-haul destinations. Critically, this slow, terrestrial travel called for attentional shifts "from distant, exotic places to our own backyards" (p. 314).

\section{Present: adventure in the age of COVID-19}

The worldwide pandemic lockdowns in January to May 2020 exponentially accelerated these attentional shifts and brought tensions associated with traditional adventure modes into stark relief. Globally, $91 \%$ of the population has experienced restricted movement, ranging from strict (e.g., China, Italy, New Zealand) to more fragmented, laissez-faire approaches (e.g., Brazil, USA) (Pew Research, 2020). In the age of COVID19 , traditional adventure travel is not only more difficult, but unethical given the imminent threat it poses to humanity. This is not hyperbole considering government admonitions to refrain from activities involving heightened risks or remote environments, such as backcountry hiking, mountain biking, and water-based activities (e.g., surfing, swimming), in order to avoid straining health systems or exposing emergency responders. 
Transmission concerns have also manifested in widespread closures of public parks and forest areas where adventure activities often unfold (e.g., NPS, n.d.).

Ironically, these restrictions have engendered a surge in adventure pursuits despite these activities being prohibited. People are taking refuge from the global crisis by seeking nature and adventure benefits. Media worldwide report unprecedented visitation at national parks and wilderness areas. In the UK, for example, grave concerns were raised over people converging on Snowdonia National Park and the potential devastation this could cause for rural health facilities. Park authorities reported their "busiest ever visitor day in living memory" and that "significant crowding on the mountain summits and trails [made] it impossible to maintain effective social distancing" (BBC, 2020). In the USA, most national parks closed following a flood of visitors coinciding with removal of entrance fees to make it "easier for the American public to enjoy the outdoors." This decision prompted outcry from park staff and condemnation by officials, "Encouraging mass park visitation amid a pandemic is irresponsible and endangers visitors and local communities" (Castleman, 2020). Even top government officials have breached adventure travel guidelines, resulting in removal from office or demotion. Possibly the most glaring of these was committed by the New Zealand Minister of Health who, on separate occasions, drove to undertake mountain biking and beach activities after issuing prohibitions on such activities (Otago Daily Times, 2020). These breaches, often at great personal or potential community costs, underscore the value we place on nature contact and adventure for our well-being and the need to identify sustainable ways of engaging in adventure moving forward.

As lockdowns have extended and restrictions on adventure travel have been clarified or tightened, we have seen creative microadventures flourishing in the most unlikely places. Sierra Club encourages people to explore their backyard, not the backcountry. Local councils promote 'isolation adventures' via webpages with adventure opportunities in nearby nature (e.g., DunedinNZ.com) and urban guidebooks revealing secret pathways connecting neighborhoods to green spaces (e.g., Jaramillo, 2012). Neighborhood 'bear hunts' have sprung up internationally; social media overflows with images of backyard camping; and people are encouraged to "skip the climbing crag and rig a ... station in [their] backyard" (Castleman, 2020). On a personal level, the first author has discovered trails around the corner and shifted focus to 'pre-schooler paced' adventures exploring the local stream, identifying birdsongs, and practicing outdoor travel skills with her family 'bubble'. However, the pinnacle of microadventure creativity may be epitomized by parents who built a homemade ski slope descending from their backyard treehouse, complete with pulley ski lift to hoist children atop (Gibbons, 2020).

\section{Future: post-pandemic adventure}

The pandemic is teaching us it is time to reimagine adventure. As our mobility and access to adventure travel gradually increase, we cannot forget these important lessons. Microadventures are not a stop-gap novelty 'for (global) emergencies only'. Rather, our vision of adventure places the microadventure philosophy and practices at the heart of post-pandemic adventure. Here we optimistically envision what post-pandemic 
adventure could look like, and why we may not only need to embrace microadventures in a post-pandemic world, but also why we may prefer them to traditional adventure travel.

What microadventures will look like. Post-pandemic adventure entails a back-to-basics approach focused on the psychological experience of adventure predicated on humanscaled mobility and locavism. An emphasis on simplicity, personal skill development, immersion in nature, curiosity, and personal insight will facilitate a return to the core of what adventure is about, elements increasingly lost in modern day adventure travel. Rather than pursuing 'more, further, faster' with advanced equipment and technology, adventure can be built around the challenges and uncertainty inherent in self-supported human-powered travel (e.g., biking, rowing/paddling, walking). Locavism and microadventures present opportunities for enhanced community connections in local places by going 'deeper' not further. These approaches retain social, psychological and financial capital for local benefit, something that is lost when community members invest psychological and financial resources in disparate, faraway places.

The pandemic will also help us reconsider the true value and ethics of exoticising faroff lands and peoples, as opposed to creating enduring place attachments in our own communities. Globalization has taught us to view our 'ordinary' neighborhoods as far less worthy of our attentional resources than fanciful distant destinations. Our current restricted mobility may unveil the overlooked natural beauty and wonders in our everyday environments. Indeed, this already seems to be unfolding in wonderfully surprising ways during lockdowns, as evidenced by an outpouring of reports highlighting people's renewed appreciation for, and engagement with, nearby nature (e.g., Hauser, 2020). The secret, understated local spots we never had the time or energy to notice are suddenly of immense value. Small trails or green spaces we never made time to explore, because we were imagining or engaging in 'grander' adventures, are now center-stage in our minds. If the pandemic has done nothing else of value, hopefully it has revealed what our own bioregion has to offer and illustrated that fulfilling adventures can be found much closer than we thought.

For historically disadvantaged populations, restricted mobility has underscored inequities in access to natural areas. People experiencing inequity and limited access to safe greenspace have creatively sought adventure in devalued local places by transforming abandoned churches, rooftops, and streets into wildscapes (e.g., Mug, 2012). Rather than romanticizing this creativity born of inequity, these endeavors highlight the importance of ensuring equal access to nature via urban planning and conservation in lower-income and highly urbanized areas. The current crisis underlines the need for greater social, psychological and financial investment in local places, particularly for disadvantaged nieghborhoods, in a post-pandemic world.

Why we need microadventures. While this pandemic may be resolved with a vaccine, climate change will not. Even if we eschew the microadventure approach, in order to mitigate climate change and avoid future pandemics, global travel must change. One clear result of the pandemic is the need to embrace domestic/bioregional travel more than its sought-after, more glamorous cousin: international tourism. The momentum of economics has prevented this shift in many popular adventure destinations, such as Queenstown, New Zealand, touted as the global 'adventure capital' (Destination 
Queenstown, n.d.). Queenstown experienced double-digit tourism growth prior to the pandemic, resulting a booming economy coupled with community uproar about visitor impacts (e.g., Jamieson, 2018). This tourism-dependent economy has screeched to a halt in a matter of weeks and the industry has called for a "serious rethink" of tourism to benefit communities and environments, with an emphasis on domestic/regional travel (Littlewood, 2020). The pandemic has done what communities the world over could not: stop economic momentum and unlock the time and space to redesign adventure destinations.

In a post-pandemic world, we envision people adventuring closer to home for a number of reasons. On the supply side, many adventure operators are small-to-medium sized businesses that may not survive travel restrictions and associated economic fallout, resulting in decreased supply of adventure travel options. Governments will be more cautious about incentivising and over-investing in tourism. On the demand side, many people will not have pre-pandemic disposable income levels necessary for traditional adventure travel. They may also worry about health risks of long-haul travel for them or their families. Even for those still seeking traditional adventure travel, global restrictions may dictate significant changes to where, how, and if they can adventure. Emirates Airlines, for example, has implemented on-site COVID-19 testing for all passengers and requires facemasks throughout boarding and flight. In addition, airport kiosks monitoring temperature, heartrate, and respiratory rates are being trialed, and it is predicted that some countries will require COVID-19 certificates and/or two-week quarantines upon arrival for all travelers (Wamsley, 2020).

Why we may prefer microadventures. In addition to these external factors that will drive a microadventure approach post-pandemic, a range of internal factors may also fuel this change. In the age of COVID-19, many people will reprioritise how they spend their time, money, psychic energy, and efforts. The (enforced) opportunities for reflection and contemplation afforded by the pandemic, and subsequent changes in economic and life situations, may create greater awareness of the intrinsic value of our immediate surroundings, of slowing down, of traveling at 'human' speeds. It may also provide more frequent adventure opportunities. Experiencing adventure more often (e.g., weekly), rather than via an extended trip every 6-18 months, may result in more consistent and enduring psychological benefits. These shifts in how we approach the world, and the values we prioritize, may mean we are not only forced to adopt microadventures, but that we may actually prefer them to pre-pandemic adventure.

Proust (1913/1982) long ago articulated a core philosophy underpinning microadventures: the real voyage of discovery consists not in seeking new landscapes but in having new eyes. If we shift our frame of reference, we can find adventure closer to home than we imagined. We can enhance well-being and reduce environmental impacts by focusing on microadventure experiences that are close by, low carbon, low consumption, and result in deeper connections to local people and places. If we can learn to seek adventure where we are, rather than in distant places, the outlook for post-pandemic adventure is hopeful.

\section{References}

Allied Market Research. (2018). Adventure tourism market overview. Retrieved from https:// www.alliedmarketresearch.com/adventure-tourism-market on 24 October 2019. 
BBC (2020). Coronavirus: 'Unprecedented' crowds in Wales despite warnings. https://www.bbc. com/news/uk-wales-51994504

Bloom, K., \& Goodnow, J. (2013). Insight and the travel experience: An exploration into the contributions of liminality. Journal of Travel and Tourism Research, 13(1/2), 143-157.

Boudreau, P., Houge Mackenzie, S. \& Hodge K. (2020). Flow states in adventure recreation: A systematic review and thematic synthesis. Psychology of Sport and Exercise, 46, 101611.

Brymer, E., \& Schweitzer, R. (2013). Extreme sports are good for your health: A phenomenological understanding of fear and anxiety in extreme sport. Journal of Health Psychology, 18(4), 477-487. doi: 10.1177/1359105312446770

Castleman, A. (2020, March 26). Ride out the coronavirus in your backyard, not the backcountry. https://www.sierraclub.org/sierra/ride-out-coronavirus-your-backyard-not-backcountry

Destination Queenstown. (n.d.). How Queenstown became the adventure capital of the world. https://www.queenstownnz.co.nz/stories/post/how-queenstown-became-the-adventure-capitalof-the-world/

Dwyer, L. (2005). Relevance of triple bottom line reporting to achievement of sustainable tourism. Tourism Review International, 9(1), 79-93. doi: 10.3727/154427205774791726

Euromonitor (2016). World travel market travel trends report. https://news.wtm.com/wp-content/ uploads/2016/11/GTR-FINAL-FINAL-ok.pdf

Ewert, A., \& Yoshino, A. (2011). The influence of short-term adventure-based experiences on levels of resilience. Journal of Adventure Education \& Outdoor Learning, 11(1), 35-50. doi: 10. 1080/14729679.2010.532986

Gibbons, T. (2020, April 12). Dad builds backyard skilift after Easter trip cancellation over coronavirus. https://www.radio.com/news/dad-builds-ski-lift-after-cancelled-easter-holiday

Goodnow, J., \& Bordoloi, S, (2017). Travel and insight on the limen: A content analysis of adventure travel narratives. Tourism Review International, 21(3), 223-239. doi: 10.3727/ $154427217 X 15022104437701$

Hauser, C. (2020, April 10). Quarantined runners log miles in backyards. https://www.nytimes. com.

Hollenhorst, S. J., Houge Mackenzie, S., \& Ostergren, D. M. (2014). The trouble with tourism. Tourism Recreation Research, 39(3), 305-319. doi: 10.1080/02508281.2014.11087003

Houge Mackenzie, S., \& Brymer, E. (2020). Conceptualizing adventurous nature sport: A positive psychology perspective. Annals of Leisure Research, 23(1), 79-91. doi: 10.1080/11745398.2018. 1483733

Humphreys, A. (2014). Microadventures: Local discoveries for great escapes. Williams Collins.

Jamieson, D. (2018, August 5). It's crunch time for Queenstown - let tourist numbers double, or shut the gate? https://www.stuff.co.nz/business/industries/105768339/its-crunch-time-for-queenstown-let-tourist-numbers-double-or-shut-the-gate

Jaramillo, J. (2012). Secret stairway walks. Mountaineer Books.

Littlewood, M. (2020, April 19). Call for serious rethink of New Zealand's approach to tourism. https://www.stuff.co.nz/timaru-herald/news/121112865/call-for-serious-rethink-of-new-zea-

lands-approach-to-tourism

Mug, K. (2012). Nature, nurture; danger, adventure; junkyard, paradise: The role of wildscapes in children's literature. In R. Keenan \& A. Jorgensen (Eds.), Urban wildscapes (pp. 80-96). Routledge.

National Park Service (NPS). (n.d.). NPS public health update. https://www.nps.gov/aboutus/ news/public-health-update.htm

Otago Daily Times (2020, April 7). PM on Clark: 'I expect better, so does New Zealand.' https:// www.odt.co.nz/news/national/pm-clark-i-expect-better-so-does-new-zealand

Pew Research (2020, April 1). More than nine-in-ten people worldwide live in countrieswith travel restrictions amid COVID-19. www.pewresearch.org

Proust, M., \& Chatto, W. (1982). Remembrance of things past (C.K.S. Moncrieff, trans.) (Original publication 1913). 
Rantala, O., Rokenes, A., \& Valkonen, J. (2018). Is adventure tourism a coherent concept? A review of research approaches on adventure tourism. Annals of Leisure Research, 21(5), 539-552. doi: 10.1080/11745398.2016.1250647

Roberts, J. W. (2018). Re-placing outdoor education: Diversity, inclusion, and the microadventures of the everyday. Journal of Outdoor Recreation, Education, and Leadership, 1(10), 20-32.

Stoddard, J. E., Pollard, C. E., \& Evans, M. R. (2012). The triple bottom line: A framework for sustainable tourism development. International Journal of Hospitality \& Tourism Administration, 13(3), 233-258.

Turner, V. (1966). The ritual process: Structure and anti-structures. Cornell.

Wamsley, L. (2020, April 15). Emirates Airline begins conducting rapid COVID-19 tests for boarding passengers. https://www.npr.org.

White, N. R., \& White, P. B. (2004). Travel as transition: Identity and place. Annals of Tourism Research, 31(1), 200-218. doi: 10.1016/j.annals.2003.10.005

Williams, P., \& Soutar, G. (2005). Close to the "edge": Critical issues for adventure tourism operators. Asia Pacific Journal of Tourism Research, 10(3), 247-261. doi: 10.1080/ 10941660500309614

World Tourism Organisation (WTO) (2014). Global report on adventure tourism. Retrieved from https://www.unwto.org/archive/middle-east/publication/global-report-adventure-tourism 